\title{
Erythrodermic psoriasis: pathophysiology and current treatment perspectives
}

REVIEW

Psoriasis:Targets and Therapy

20 July 2016

Number of times this article has been viewed

Rasnik K Singh,' Kristina M Lee, ${ }^{2}$ Derya Ucmak, ${ }^{2}$ Merrick Brodsky, ${ }^{3}$ Zaza Atanelov, ${ }^{4}$ Benjamin Farahnik, ${ }^{5}$ Michael Abrouk, ${ }^{3}$ Mio Nakamura, ${ }^{2}$ Tian Hao Zhu, ${ }^{6}$ Wilson Liao ${ }^{2}$

'Department of Medicine, University of California - Los Angeles, David Geffen School of Medicine, Los Angeles, 2Department of Dermatology, University of California - San Francisco, San Francisco, ${ }^{3}$ Department of Medicine, University of California - Irvine, School of Medicine, Irvine, CA, ${ }^{4}$ Department of Medicine, New York Medical College, Valhalla, NY, ${ }^{5}$ Department of Medicine, University of Vermont College of Medicine, Burlington, VT, ${ }^{6}$ Department of Medicine, University of Southern California Keck School of Medicine, Los Angeles, CA, USA

\section{Video abstract}

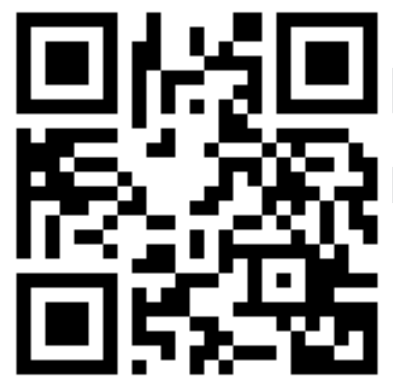

Point your SmartPhone at the code above. If you have a QR code reader the video abstract will appear. Or use: bttp://youtu.be/Imo2WwZhLll

Correspondence: Rasnik K Singh Department of Dermatology, University of California - San Francisco, 2340 Sutter Street, Room N43I, Box 0808, San Francisco, CA 94II5, USA

Tel +I 4I5 4768364

Fax + I 4154768837

Email Rasnik.s@gmail.com
Abstract: Erythrodermic psoriasis (EP) is a rare and severe variant of psoriasis vulgaris, with an estimated prevalence of $1 \%-2.25 \%$ among psoriatic patients. The condition presents with distinct histopathologic and clinical findings, which include a generalized inflammatory erythema involving at least $75 \%$ of the body surface area. The pathogenesis of EP is not well understood; however, several studies suggest that the disease is associated with a predominantly T helper 2 (Th2) phenotype. Given the morbidity and potential mortality associated with the condition, there is a need for a better understanding of its pathophysiology. The management of EP begins with a comprehensive assessment of the patient's presentation and often requires multidisciplinary supportive measures. In 2010, the medical board of the US National Psoriasis Foundation published consensus guidelines advocating the use of cyclosporine or infliximab as first-line therapy in unstable cases, with acitretin and methotrexate reserved for more stable cases. Since the time of that publication, additional information regarding the efficacy of newer agents has emerged. We review the latest data with regard to the treatment of EP, which includes biologic therapies such as ustekinumab and ixekizumab.

Keywords: erythrodermic psoriasis, EP, pathogenesis, pathophysiology, treatment, biologics

\section{Introduction}

Psoriasis is a chronic inflammatory skin condition affecting roughly $2 \%$ of the population. ${ }^{1}$ Erythrodermic psoriasis (EP) is a rare and severe variant of the disease, with an estimated prevalence among psoriatic patients ranging from $1 \%-2.25 \%{ }^{2}$ Furthermore, psoriatic erythroderma is the most common cause of erythroderma, responsible for $\sim 25 \%$ of all cases. ${ }^{2,3}$ Although the class I antigens HLA-Cw6, HLA-B57, HLA-B13, and HLA-B17 have been associated with psoriasis vulgaris (PV) and IL36RN mutations have been associated with pustular psoriasis, very little is known about the genetic basis of EP. ${ }^{4,5}$ A recent retrospective epidemiological study in 60 patients with EP revealed a 3:1 male-to-female ratio, an average age of 53.7 years, a positive history of psoriasis in $78 \%$ of cases, an identifiable trigger factor in $53 \%$ of cases, a need for systemic therapy in $55 \%$ of cases, clinical improvement in $69.4 \%$ of cases, disease recurrence in $15 \%$ of cases, and finally three cases of septicemia and one case of stroke. ${ }^{6}$ The average age of onset and male-to-female ratio reported in this study corroborated those of an older epidemiological study reporting on 50 patients with EP. ${ }^{2}$

\section{Clinical features and presentation}

EP presents with generalized cutaneous findings such as erythema, edema, pruritus, ill-defined psoriatic plaques, scaling, hair loss, and occasionally exudative lesions and 
palmoplantar or diffuse desquamation..$^{7-9}$ Nail changes are very common to EP and can range from mild pitting to severe onychodystrophy, more commonly involving the fingernails than the toenails. ${ }^{2,8,10}$ In addition, patients can have systemic symptoms of fever, tachycardia, fatigue, malaise, chills, dehydration, lymphadenopathy, arthralgia, myalgia, insomnia, sweats, diarrhea, constipation, weight changes, allodynia, and rarely high output heart failure (due to excessive water loss and edema) and cachexia. ${ }^{8,11,12}$ Laboratory results may show massive protein and fluid loss, leukocytosis, anemia, elevated C-reactive protein and erythrocyte sedimentation rate, electrolyte abnormalities, temperature irregularities (hypothermia or hyperthermia), and rarely abnormal liver function tests. ${ }^{2,13,14}$

To clinically diagnose EP, many authors suggest that there must be generalized inflammatory erythema, with or without exfoliation, involving at least $75 \%$ of the body surface area. Other authors argue that at least $90 \%$ of the body surface area must be affected. ${ }^{7,8,11}$ If clinical suspicion is high, the diagnosis can be confirmed with histologic analysis of EP, which demonstrates an epidermal perivascular infiltrate of lymphocytes and eosinophils, dilated capillaries, and hyperkeratosis. Additional histological features of EP include some features of classical psoriasis, including parakeratosis, acanthosis, spongiosis, Munro micro-abscesses, and occasional apoptotic keratinocytes. ${ }^{13,15,16}$ However, due to exfoliation and loss of the epidermal stratum corneum in EP, Munro micro-abscesses and parakeratosis may not be prominent histologically. ${ }^{13}$ Furthermore, in order to confirm a diagnosis of EP, clinicians must rule out other plausible causes of erythroderma such as atopic dermatitis, pityriasis rubra pilaris, drug eruptions, contact dermatitis, seborrheic dermatitis, immunobullous disorders, connective tissue disorders, and Sezary syndrome and other malignancies. ${ }^{8,13,17}$

Although the aforementioned parameters are sufficient to make a diagnosis of EP, it is important to note that the disease can be categorized further into two general clinical subtypes. The first is characterized by the presence of psoriatic plaques with gradual additional development of a generalized erythroderma in which the psoriatic plaques remain differentiable from the erythroderma. The disease course is relatively stable and prognosis is favorable in this form of EP. The second subtype, which is more commonly seen in the setting of psoriatic arthritis, is often characterized by rapid whole body erythema and lack of demarcated psoriatic plaques. The disease course is relatively unstable and is more likely to be associated with abnormal vital signs and laboratory values. Accordingly, prognosis is not as favorable and there is appreciable mortality. The first clinical subtype is often associated with a more chronic and prolonged course, while the second subtype is more likely to be acute, rapidly progressive, and relapsing. ${ }^{11,18}$

Other rare types of EP include congenital EP and EP secondary to an environmental trigger (Table 1). ${ }^{19-21}$ Documented environmental triggers include sunburn, skin trauma, emotional stress, alcoholism, systemic illness, drug exposure, chemical exposure (such as to computed tomography contrast material or topical tar), and rapid withdrawal from medications known as the rebound phenomenon. ${ }^{11,13,14}$ Common antipsoriatic medications that may lead to the rebound phenomenon include topical and oral steroids, efalizumab, and methotrexate. ${ }^{11,22,23}$ Systemic illnesses that have been known to trigger EP include human immunodeficiency virus, leukemia, T-cell lymphoma, and gout. ${ }^{11,24,25}$ Finally, pharmaceutical drugs that have been reported in the literature to trigger EP include acitretin, etretinate, infliximab, lithium, antimalarials, and trimethoprim/sulfamethoxazole. ${ }^{10,26,27}$

Because there is such a large list of possible EP triggers, it is sometimes difficult to differentiate the trigger from post-EP-related comorbidities. Therefore, it is important to be aware that EP patients commonly acquire superinfections of the skin and blood with Staphylococcus aureus and Group A Streptococcus that may lead an unaware clinician to conclude that the infection was a trigger to the EP. ${ }^{8,12}$ Due to a defective skin barrier, EP patients can present with severe cellulitis, erysipelas, and sepsis. ${ }^{12,13}$ Other complications include pneumonia, endocarditis, and osteomyelitis. ${ }^{8,14}$

\section{Pathogenesis}

The pathogenesis of EP is yet to be fully understood compared to classic PV (Table 2). ${ }^{11}$ The pathogenesis of PV is known to derive from abnormal interactions between T-lymphocytes, dendritic cells, keratinocytes, neutrophils, and proinflammatory cytokines, leading to activation of the Th17 and Th1 immune axes. ${ }^{28}$ In contrast, the paucity of information regarding EP has led us to rely on hints of information derived from smaller studies such as case reports, case series, and a small number of studies comparing EP patients to PV patients and healthy controls. In 2005, scientists demonstrated a statistically significant increase in serum immunoglobulin E in EP compared to PV patients. This disparity was attributed to a Th1/Th2 imbalance in favor of Th2 differentiation. ${ }^{29}$ A more recent study involving $16 \mathrm{EP}$ patients furthered the notion that EP is characterized by a bias toward the Th2 program. This study uncovered three important discoveries regarding the pathogenesis of EP: first, that the ratio of Th1/Th2 was 
Table I Summary of erythrodermic psoriasis triggers

\begin{tabular}{|c|c|c|}
\hline Type of trigger & Examples & References \\
\hline Environmental & Sunburn, skin injury/trauma, emotional stress, alcoholism, infection ${ }^{\mathrm{b}}$ & $5,15,75$ \\
\hline Chemical reaction & Bupropion use in smokers ${ }^{\mathrm{a}}$, CT contrast $^{\mathrm{a}}$, topical tar & $65^{\mathrm{a}}, 66^{\mathrm{a}}, 75$ \\
\hline Systemic illness & HIV, leukemia, T-cell lymphoma, paraneoplastic presentation, gout ${ }^{\mathrm{a}}$ & $5,22,45^{a}$ \\
\hline Pharmaceutical drugs & Lithium, antimalarials, TMP/SMX, infliximab, acitretin & $38,46,51$ \\
\hline Rebound phenomenon & Topical and oral steroids, efalizumab, methotrexate & $5,30,32$ \\
\hline
\end{tabular}

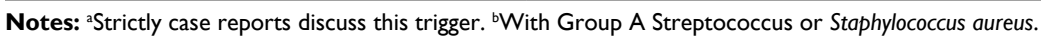

Abbreviations: CT, computed tomography; HIV, human immunodeficiency virus; TMP/SMX, trimethoprim/sulfamethoxazole.

Table 2 Key studies examining biomarkers in erythrodermic psoriasis

\begin{tabular}{|c|c|c|c|c|}
\hline Study & Patient demographics & Biomarkers examined & Key results & Implications \\
\hline Zhang et $\mathrm{al}^{30}$ & $\begin{array}{l}16 \text { patients with EP; } 20 \\
\text { patients with PV; I5 } \\
\text { healthy controls }\end{array}$ & $\begin{array}{l}\text { Levels of IFN- } \gamma \text {, IL-2, } \\
\text { IL-4 and IL-I0 (serum); } \\
\text { expression levels of T-bet/ } \\
\text { GATA-3 (skin lesion and } \\
\text { PBMCs); ThI and Th2 } \\
\text { levels (blood) }\end{array}$ & $\begin{array}{l}\text { Levels of IL- } 4 \text { and IL-I } 0 \text { in EP patients were } \\
\text { significantly higher than those in PV patients } \\
\text { and healthy controls }(P<0.05) ; \mathrm{ThI} / \mathrm{Th} 2 \text { ratio } \\
\text { was dramatically lower than in PV patients } \\
(P<0.0 \mathrm{I}) \text {; ratio of IFN- } \gamma / \mathrm{IL}-4 \text { and T-bet/ } \\
\text { GATA-3 in EP patients were both }<1.0\end{array}$ & $\begin{array}{l}\text { EP patients may have an } \\
\text { increased Th2 response, } \\
\text { which could be an } \\
\text { important mechanism in EP } \\
\text { pathogenesis }\end{array}$ \\
\hline Deeva et $\mathrm{a}^{31}$ & $\begin{array}{l}30 \text { patients with severe } \\
\text { forms of pso; ten healthy } \\
\text { controls }\end{array}$ & $\begin{array}{l}\text { IL-4, IL-6, IL-I0, IL-I3, } \\
\text { MCP-I, VEGF, and } \\
\text { PDGFbb (plasma) }\end{array}$ & $\begin{array}{l}\text { Increased plasma IL-4, IL-6, MCP-I, PDGFbb, } \\
\text { VEGF in pso patients compared to healthy } \\
\text { controls; EP patients showed a significant } \\
\text { increase in IL-I } 3 \text { and MIPI-beta compared to } \\
\text { healthy controls }\end{array}$ & $\begin{array}{l}\text { Increased Th2 response } \\
\text { and grossly dysregulated } \\
\text { angiogenic factors } \\
\text { are common to the } \\
\text { pathogenesis of pso and EP }\end{array}$ \\
\hline Kano et $\mathrm{al}^{33}$ & One patient with EP & $\begin{array}{l}\text { IFN- } \gamma \text { producing CD8+ } \\
\text { T-cells (blood); IL- } 4 \text { and } \\
\text { IL-I } 3 \text { producing CD4+ and } \\
\text { CD8+ T-cells (blood) }\end{array}$ & $\begin{array}{l}\text { Increased frequency of IFN- } \gamma \text { producing } \\
\text { CD8+ T-cells during the EP stage; IL- } 4 \text { and } \\
\text { IL-I } 3 \text { producing CD4+ and CD8+ T-cells } \\
\text { were remarkably high during resolution of EP }\end{array}$ & $\begin{array}{l}\text { Shift toward Th2 cytokine } \\
\text { predominance contributes } \\
\text { to resolution of severe pso }\end{array}$ \\
\hline Li et $\mathrm{al}^{29}$ & $\begin{array}{l}16 \text { patients with } \mathrm{EP} \text {; } \\
48 \text { patients with } \mathrm{PV} \text { as } \\
\text { controls }\end{array}$ & $\lg \mathrm{E}$ (serum) & $\begin{array}{l}\text { Serum IgE elevated in EP group compared to } \\
\text { controls }(P<0.00 I)\end{array}$ & $\begin{array}{l}\text { EP may be a Th2 dominant } \\
\text { disorder; role of serum IgE } \\
\text { needs to be investigated } \\
\text { further }\end{array}$ \\
\hline Groves et $\mathrm{a}^{138}$ & $\begin{array}{l}14 \text { patients with } \\
\text { erythroderma; } 17 \text { healthy } \\
\text { controls }\end{array}$ & $\begin{array}{l}\text { ICAM-I, VCAM-I, and } \\
\text { E-selectin levels (plasma) }\end{array}$ & $\begin{array}{l}\text { In erythroderma, median ICAM-I, VCAM- } \\
\text { I, and E-selectin levels were significantly } \\
\text { elevated }\end{array}$ & $\begin{array}{l}\text { Plasma intercellular } \\
\text { adhesion molecules } \\
\text { may contribute to the } \\
\text { immunosuppressive state } \\
\text { in EP due to abnormal cell } \\
\text { adhesion mechanisms }\end{array}$ \\
\hline
\end{tabular}

Abbreviations: EP, erythrodermic psoriasis; PV, psoriasis vulgaris; IFN, interferon; IL, interleukin; T-bet/GATA-3, T-box expressed in T-cells/GATA-binding protein-3; PBMC, peripheral blood mononuclear cells; Th, T helper cells; pso, psoriasis; MCP-I, monocyte chemoattractant protein-I; VEGF, vascular endothelial growth factor; PDGFbb, platelet derived growth factor-bb; pso, psoriasis; MIPI-beta, macrophage inflammatory protein I beta; IgE, immunoglobulin E; AD, atopic dermatitis; TNF- $\alpha$, tumor necrosis factor-alpha; HBD-3, human beta defensin-3; ICAM-I, intercellular adhesion molecule-I; VCAM-I, vascular cell adhesion molecule-I; E-selectin, endotheliumspecific inducible adhesion molecule.

dramatically lower in EP compared to PV patients; second, levels of interleukin (IL)-4 and IL-10 were significantly higher in EP patients than both PV and healthy patients; and finally, ratios of interferon (IFN)- $\gamma /$ IL-4 and T-box expressed in T-cells/GATA-binding protein-3 (GATA-3) in EP patients were both $<1.0$, representing a reversal when compared with the other two groups. Higher levels of transcription factor GATA-3 - a key regulator of Th2 development from naïve Th cells - and IL- 4 - a signature Th 2 cytokine - were indicative of Th2 predominance in EP patients. The authors also noted that compared to healthy controls, EP patients had higher serum levels of the Th1 cytokines IFN- $\gamma$ and IL-2 as well as the Th 2 cytokines IL-4 and IL-10. ${ }^{30}$ Another study showed that the cytokine, chemokine, and angiogenic growth factor profile for severe psoriatic disease, including very severe plaque psoriasis, psoriatic arthritis, and EP, was characterized by a significant increase in plasma levels of IL-4, IL-6, monocyte chemoattractant protein-1, platelet-derived growth factor$\mathrm{bb}$, and vascular endothelial growth factor, whereas only EP patients had significantly increased IL-13 and macrophage inflammatory protein-1-beta compared to healthy controls. ${ }^{31}$ These findings suggest that an increased $\mathrm{Th} 2$ response and grossly dysregulated angiogenic factors are features of EP.

Interestingly, a previous study had shown that IL-4, the signature Th2-inducing cytokine, was safe and effective in the treatment of plaque-type psoriasis. The authors attributed its efficacy to the induction of the Th2 pathway in skin-infiltrating lymphocytes. ${ }^{32}$ The study was followed 
by investigations demonstrating high levels of CD8+ T-cells during the erythrodermic stage versus high levels of IL-4 and IL-13 producing CD4+ and CD8+ T-cells during the resolution stage of EP, suggesting a shift toward Th2 cytokine predominance contributing to the resolution of severe psoriasis such as EP. ${ }^{33}$ Accordingly, many psoriasis therapeutics are either directed against T-cells, tumor necrosis factor-alpha (TNF- $\alpha$ ), the IL-12/IL-23 axis, or redirect cellular immune responses into a protective IL-4-dominated Th2 phenotype. ${ }^{34}$ Considering all studies together, it remains to be clarified whether the Th2 phenotype seen in EP is associated with disease promotion or with a feedback response resulting in resolution of the disease.

Given their established importance in PV, the contribution of Th17 cells to EP pathogenesis has also recently been investigated. Th17 cells secrete IL-17, IL-22, and IFN- $\gamma$, inducing production of inflammatory chemokines by T-cells, dendritic cells, and neutrophils. ${ }^{35}$ Using immunohistochemical analysis, Moy et al found Th17 to be the most predominant T-cell subset after Th2 in EP lesions. The authors also observed significant immunologic overlap of Th17 cells in EP and erythrodermic atopic dermatitis. ${ }^{36}$

At a molecular level, TNF- $\alpha$ has been shown to be overexpressed in plaque psoriatic lesions. It has been suggested that rapid systemic release of TNF- $\alpha$ in EP may be responsible for disease onset and severity. ${ }^{37}$ It is also suspected that the presence of circulating adhesion molecules, such as intercellular adhesion molecule-1, vascular cell adhesion molecule-1, and E-selectin, may contribute to the immunosuppressed state in EP due to interference with normal cellular adhesion mechanisms required for immune responses. ${ }^{38} \mathrm{EP}$ has additionally been associated with a dermatogenic enteropathy leading to hypocalcemia and hypophosphatemia, both of which may be exacerbated by excess calcium and phosphate excretion through the skin during EP flares. ${ }^{39}$

\section{Management of EP General considerations}

Initial management of EP must include correction of any fluid, protein, and electrolyte abnormalities; a nutritional assessment; prophylaxis against hypothermia; and treatment of any secondary infections. Sepsis caused by skin pathogens, most commonly Staphylococcus aureus, is a particularly severe and potentially fatal complication that has been reported. ${ }^{2,6,40}$

In 2010, the medical board of the US National Psoriasis Foundation published consensus guidelines regarding the appropriate management of EP once initial stabilizing measures have been undertaken. They advocate the use of cyclosporine or infliximab as first-line therapy in acute and unstable cases. For more stable cases, on the other hand, acitretin and methotrexate are the preferred agents. Secondline options include etanercept and combination therapy. ${ }^{8}$ However, since the time of that publication, additional information regarding the efficacy of newer agents has emerged. Later, we review the latest data with regard to the treatment of EP.

\section{Topical therapy}

With the development of more potent and targeted therapies, the use of topicals in EP has become less common. Nevertheless, they may be helpful for nontoxic patients or as adjunct therapy for recalcitrant lesions in more severe disease. ${ }^{13,34}$ In these cases, use of medium potency topical steroids under occlusive dressing, colloidal oatmeal baths, topical emollients, topical vitamin D analogs, and various combinations of the aforementioned has been reported in the literature. Of note, coal tar is generally not recommended during the acute phase of EP given its ability to cause substantial skin irritation that may result in Koebner's phenomenon. ${ }^{41}$

\section{Topical steroids}

A case series of two patients treated with twice-daily topical betamethasone dipropionate ointment, colloidal oatmeal baths, and total body occlusion reported significant skin clearing within three to four hospital days. Both patients had $>80 \%$ body surface area involvement with unstable vitals and laboratory abnormalities on admission. ${ }^{42}$ Steroids are often used as a temporizing or adjunctive measure while an alternative treatment is introduced. ${ }^{13}$ For instance, clobetasol $0.05 \%$ for body and desonide $0.05 \%$ for face have been used successfully in combination with methotrexate in a severe patient requiring intensive care unit hospitalization. ${ }^{43}$

\section{Topical vitamin $D$ analogs}

The vitamin $\mathrm{D}$ analogs comprise a rising first-line therapy for mild-to-moderate plaque psoriasis given their ability to abrogate skin cell proliferation, enhance skin cell differentiation, and modulate immunologic factors that are involved in disease etiology. ${ }^{44,45}$ Calcipotriol and calcitriol generally should not be used for situations in which patients have a high risk of systemic absorption, such as in severe EP. ${ }^{41}$ Nevertheless, two groups effectively incorporated a vitamin D analog as one arm of a combination therapy to treat erythrodermic manifestations. van der Vleuten et al performed a left/right comparison study in a patient who presented with recalcitrant 
EP that had failed treatment with methotrexate, topical steroids, and acitretin. Calcipotriol application was begun only after a minor improvement had been achieved with $5 \mathrm{mg} / \mathrm{kg} / \mathrm{d}$ of cyclosporine. The authors noted a rapid and significant improvement on the side of the patient's body treated with the vitamin $\mathrm{D}$ analog. The whole body was then treated with $100 \mathrm{~g} / \mathrm{wk}$ of calcipotriol in conjunction with low-dose ultraviolet $\mathrm{B}$, leading to marked improvement in 4 weeks. ${ }^{46}$ As an alternative combination therapy, the literature also supports the use of calcipotriene with adalimumab. ${ }^{47}$

\section{Phototherapy}

Phototherapy is an effective, first-line treatment for moderateto-severe plaque psoriasis that works by inhibiting keratinocyte proliferation, promoting keratinocyte apoptosis, and dampening the inflammatory Th1 and Th17 pathways. ${ }^{48}$ The use of phototherapy in acute, fulminant EP is discouraged given the risk of koebernization. ${ }^{13}$ However, phototherapy can play a role in long-term management of EP once the disease course becomes more stable. ${ }^{8}$ One case report supports the use of low-dose ultraviolet $B$ in combination with local calcipotriol for long-term maintenance therapy of EP. ${ }^{46}$ It has also been suggested that phototherapy can be a helpful adjunct in instances where EP is refractory to acitretin monotherapy. ${ }^{49}$

\section{Systemic agents}

\section{Second-generation retinoids}

Etretinate and its active metabolite, acitretin, are effective systemic treatments for moderate-to-severe psoriasis and other hyperkeratotic disorders (Table 3 ). They function to normalize keratinocyte proliferation and differentiation, regulate sebaceous gland activity, and modulate local inflammatory responses. ${ }^{50}$ Side effects are dose-dependent and include skin desquamation, cheilitis, xerosis, pruritus, and hair loss. ${ }^{27}$ Retinoids are also known to be potent teratogens; therefore, the use of these agents in women of childbearing potential is heavily regulated. ${ }^{51}$

According to expert consensus, acitretin is considered a high-priority agent for stable cases of EP as it has a relatively slower onset of action. ${ }^{8} \mathrm{Koo}^{52}$ describes a sequential therapy for EP in which patients are started on $25 \mathrm{mg} / \mathrm{d}$ of acitretin, which can then be increased by 10-25 mg every 2-4 weeks until the maximally tolerated dose is reached.

A meta-analysis of 12 patients receiving $25-35 \mathrm{mg} / \mathrm{d}$ of acitretin noted clinical remission or significant improvement of EP in $83.3 \%$ of cases. ${ }^{53}$ Polat and Sereflican found $50 \mathrm{mg} / \mathrm{d}$ of acitretin to be similarly effective in one patient with concomitant EP and elephantiasis nostras verrucosa. After 1 month of treatment, the patient had near-complete resolution of his lesions and remained clear at 2-month follow-up. ${ }^{54}$ However, a 4-month trial of acitretin at the same dose in another patient failed to produce any clinical improvement. It is important to note, though, that this patient was significantly overweight and may have been underdosed. ${ }^{55}$

The second-generation retinoids have also been used in combination with other systemic agents, such as cyclosporine and infliximab. Three patients treated with $0.5-0.8 \mathrm{mg} / \mathrm{kg} / \mathrm{d}$ of etretinate and 3-4 mg/kg/d of cyclosporine experienced significant disease resolution within a few weeks. ${ }^{56}$ The acitretin/cyclosporine combination was ineffective in four other patients, although in one of the cases, the maximum daily dose of acitretin was only $20 \mathrm{mg} .{ }^{46,57}$ In addition, a case series examining acitretin/infliximab reported $>90 \%$ improvement of erythrodermic manifestations in four patients. ${ }^{58}$

Interestingly, there are also case reports describing acitretin- and etretinate-induced EP, which ultimately resolved after the drug was discontinued and replaced with cyclosporine. ${ }^{27,59,60}$ It is unclear why the retinoids provoked erythroderma in these cases. Systemic retinoids have also exhibited reduced efficacy in the context of low serum albumin levels as it is thought that transport proteins such as albumin are necessary for the migration of acitretin into peripheral tissues. ${ }^{61}$

\section{Methotrexate}

Methotrexate is an immunosuppressive drug that inhibits the enzyme dihydrofolate reductase. Oral systemic therapy with methotrexate is a first-line option for patients with plaque

Table 3 Studies examining conventional systemic agents as monotherapy in erythrodermic psoriasis

\begin{tabular}{|c|c|c|c|c|}
\hline Conventional agent & Total patients & Dosing range & Outcome & Responders n (\%) ${ }^{a}$ \\
\hline Acitretin $^{52-54}$ & 14 & $25-50 \mathrm{mg} / \mathrm{d}$ & Complete remission & II (78.6) \\
\hline Methotrexate ${ }^{10,20,62-66}$ & 60 & $5-40 \mathrm{mg} / \mathrm{wk}$ & $\begin{array}{l}\text { Complete remission or good-to-excellent } \\
\text { response }\end{array}$ & $50(83.3)$ \\
\hline Cyclosporine ${ }^{13,25,27,28,76,77}$ & 42 & $\begin{array}{l}\mathrm{I} .5-4.2 \mathrm{mg} / \mathrm{kg} / \mathrm{d} \\
\text { starting dose }\end{array}$ & $\begin{array}{l}\text { Complete remission or significant } \\
\text { improvement }\end{array}$ & $36(85.7)$ \\
\hline
\end{tabular}

Note: aPartial or complete response.

Abbreviations: $\mathrm{d}$, day; wk, week. 
psoriasis who have inadequate control on topicals alone. Like acitretin, methotrexate also has a slower onset of action and is considered a high-priority agent for more stable cases of EP. It is either taken orally or administered as a once-weekly injection, commonly $5-7.5 \mathrm{mg}$ or $15-20 \mathrm{mg}$, and can be supplemented with $1 \mathrm{mg}$ daily folic acid. Long-term use of methotrexate may increase the risk of hepatotoxicity, hepatic fibrosis, and bone marrow suppression. ${ }^{62}$

A retrospective analysis of 21 patients with severe psoriasis or EP treated with an initial dose of 5-7.5 mg/wk reported complete remission in $62 \%$ of cases and partial remission in $28.5 \%$ of cases. Mean remission period lasted 14 months. ${ }^{63}$ Several case reports also describe EP resolution within 3 weeks to 3 months using the same dosing range. One of these patients was even continued on maintenance therapy for 2 years with lasting remission. ${ }^{10,19,64}$

Three retrospective studies totaling 53 patients investigating $15-40 \mathrm{mg} / \mathrm{wk}$ of methotrexate reported good-to-excellent responses in 43 patients $(81 \%)$, moderate responses in seven patients $(13 \%)$, and poor responses in three patients $(6 \%) .{ }^{65-67}$ Two case reports also support the use of $15 \mathrm{mg} / \mathrm{wk}$ in patients presenting with diffuse EP. Both patients began to experience significant skin clearing within a few weeks. Notably, one patient was also receiving concomitant compound glycyrrhizin, an agent that is thought to block production of IL-8. ${ }^{43,68}$ Methotrexate has been combined with several other agents for the treatment of EP, including with infliximab ${ }^{55,69-71}$; with etretinate reporting satisfactory results ${ }^{72}$; and with cyclosporine or etanercept reporting excellent results. ${ }^{64,73}$

\section{Cyclosporine}

Cyclosporine is an immunosuppressive agent that blocks IL-2 transcription, thereby impairing the growth and activity of T-cells. Cyclosporine is approved by the US Food and Drug Administration for the treatment of severe plaque psoriasis in immunocompetent adults. ${ }^{74}$ Given its rapid onset of action, cyclosporine is considered a critical first-line drug for the control of unstable cases of EP. More severe disease often requires a starting dose of $5 \mathrm{mg} / \mathrm{kg} / \mathrm{d}$. Case series and reports advocate the use of cyclosporine in the treatment of EP at doses of $1.5-5 \mathrm{mg} / \mathrm{kg} / \mathrm{d}$ for 2 weeks to 4 months. ${ }^{12,24,26,27,75,76}$ The largest case series $(n=33)$ described complete disease remission in $67 \%$ of patients after 3 months and an overall response rate of $94 \% .{ }^{24}$ Cyclosporine can also be used in combination with topical or systemic agents, such as acitretin and etretinate, in order to reduce the dose, duration, and adverse effects of each individual agent. ${ }^{46,56,57}$ At the time of EP remission (total resolution of skin lesions), cyclosporine can slowly be tapered by $0.5 \mathrm{mg} / \mathrm{kg}$ every 2 weeks until total discontinuation or reappearance of signs of disease. ${ }^{12,24}$ Nephrotoxicity is the most significant potential side effect of cyclosporine; therefore, a $>30 \%$ elevation of serum creatinine must prompt a reduction in dose or cessation of therapy.

\section{Mycophenolate mofetil}

Mycophenolate mofetil is another immune suppressant that selectively inhibits activated lymphocytes. It has efficacy as a monotherapy for moderate-to-severe psoriasis in several case reports, small clinical studies, and a randomized controlled trial. ${ }^{77-80}$ Use of mycophenolate mofetil in two patients with severe EP has also been reported in the literature. Over a 6 -week period, both patients experienced $70 \%$ skin improvement with no notable side effects or disease relapse after drug cessation. ${ }^{78}$ Of note, mycophenolate mofetil is teratogenic and should not be used during pregnancy.

\section{Biologics}

Biologic therapy encompasses an emerging category of drugs that target specific cytokines of the immune system. Given their enhanced selectivity, these agents are a promising alternative to the conventional immunosuppressants, such as methotrexate and cyclosporine. Certain categories of biologics have been adopted for the treatment of EP, including the TNF- $\alpha$ inhibitors, IL-12/IL-23 inhibitors, and most recently, the IL-17A inhibitors (Table 4).

Baseline screening prior to beginning treatment with a biologic includes a tuberculin skin test or IFN- $\gamma$-release assay for tuberculosis (QuantiFERON Gold), updated immunizations, hepatitis $\mathrm{B}$ and $\mathrm{C}$ and human immunodeficiency virus tests, and basic blood and chemistry laboratories including liver function tests. ${ }^{81}$

\section{TNF- $\alpha$ inhibitors}

\section{Etanercept}

Etanercept is a soluble TNF-receptor fusion protein that acts as a decoy for endogenous TNF- $\alpha$. This interaction inhibits the biological inflammatory cascade of TNF- $\alpha$. Etanercept is administered subcutaneously once to twice weekly (maximum individual dose of $50 \mathrm{mg}$ ). A case series following ten patients with EP reported that eight of ten patients (80\%) attained PASI50 (50\% or greater reduction of the psoriasis area and severity index) and five patients (50\%) reached PASI75 at 12 weeks. At the end of the 24 weeks, six of the total ten patients $(60 \%)$ had achieved and maintained PASI75. ${ }^{82}$ A multicenter retrospective study provided six further cases of EP treated with etanercept, with four of six (67\%) achieving PASI75 between weeks 12 and 14. Clearance, defined as PASI90, was obtained in two of six (33.3\%) 
Table 4 Studies examining biologic monotherapy in erythrodermic psoriasis

\begin{tabular}{lllll}
\hline Biologic agent & Total patients & Reaching PASI50 $\mathbf{n}(\%)^{\mathbf{a}}$ & \# Reaching PASI75 (\%) & Earliest clinical response \\
\hline Etanercept $^{7,81-83}$ & 18 & $14(77.8)$ & $12(66.7)$ & 12 weeks \\
Adalimumab $^{7,9,46}$ & $\mathrm{I}$ & $6(54.5)$ & $6(54.5)$ & 12 weeks \\
Infliximab $^{7,57,89-95}$ & 55 & $30(54.5)$ & $30(54.5)$ & 48 hours \\
Golimumab $^{36}$ & $\mathrm{I}$ & $1(100)$ & $1(100)$ & 4 weeks \\
Ustekinumab $^{7,18,24,54,85-87,99}$ & 40 & $34(85)$ & $31(77.5)$ & 4 weeks \\
Ixekizumab $^{101}$ & 8 & $8(100)$ & $8(100)$ & 12 weeks \\
\hline
\end{tabular}

Notes: aPASI50, 50\% reduction in psoriasis area and severity index; ${ }^{\mathrm{b} A S I 75,75 \%}$ reduction in psoriasis area and severity index.

cases with a mean delay of 16 weeks. ${ }^{7}$ Two individual case reports additionally support long-term management of EP using etanercept monotherapy with excellent responses. ${ }^{83,84}$

Etanercept has also been used concomitantly with methotrexate in a pediatric patient presenting with recalcitrant EP. Her erythrodermic manifestations gradually subsided over a 3 -month period and were not noted to reappear throughout 2-year follow-up. ${ }^{64}$

\section{Adalimumab}

Adalimumab is a fully human monoclonal antibody against TNF- $\alpha$. It is administered subcutaneously at an initial dose of $80 \mathrm{mg}$ at week 0 , followed by $40 \mathrm{mg}$ every other week starting at week $1 .{ }^{85}$ Two case reports, as well as one multicenter, retrospective study, support the use of adalimumab in EP. The multicenter study reported that $50 \%$ of the subjects had a $75 \%$ reduction in PASI score from baseline by $12-14$ weeks after treatment onset. ${ }^{7}$ Mumoli et a ${ }^{47}$ similarly observed significant disease remission in a patient who was treated with adalimumab for 12 weeks. Lastly, a complicated EP patient with concomitant hepatitis $\mathrm{C}$ virus infection and hemophilia remarkably achieved remission at week 3 of treatment with adalimumab. ${ }^{9}$ Interestingly, several patients who were treatment resistant to adalimumab and other anti-TNF- $\alpha$ agents had eventual success with ustekinumab. ${ }^{17,55,86-88}$

\section{Infliximab}

Infliximab is a chimeric anti-TNF- $\alpha$ monoclonal antibody that interacts with both soluble and membrane-bound TNF- $\alpha$. This interaction results in decreased epidermal T-cell infiltration. For the treatment of severe plaque psoriasis, $5 \mathrm{mg} / \mathrm{kg}$ is administered intravenously at weeks 0,2 , and 6 , with maintenance dosing every 8 weeks thereafter. ${ }^{89}$ Given its route of administration, infliximab has a relatively quick onset of action that is comparable to that of cyclosporine. Therefore, expert consensus considers the drug an additional first-line option for unstable cases of EP. Several case reports and series, as well as one multicenter clinical trial, support the use of infliximab as a monotherapy in EP. Together, these studies describe 52 patients, with 34 (65\%) exhibiting significant improvement as defined by at least a $50 \%$ reduction in PASI score from baseline ${ }^{7,58,90,91}$ or by a physician's global assessment of "clear" or "almost clear". ${ }^{92-96}$ Infliximab has also successfully been combined with other systemic agents, such as methotrexate and acitretin, with excellent clinical results. ${ }^{58,69,70,97}$

However, a couple of case reports suggest that infliximab may lose efficacy after successive infusions. In these patients, no further reduction in PASI was appreciated after 14 weeks and 30 weeks of treatment. ${ }^{84,87}$ It is thought that this phenomenon may occur due to development of anti-infliximab antibodies. Interestingly, it has also been suggested that development of antinuclear antibodies and anti-double-stranded DNA antibodies on anti-TNF- $\alpha$ treatment may signal forthcoming treatment failure ${ }^{88}$ Larger and longer term clinical trials may help decide whether surveillance for these antibodies is warranted.

\section{Golimumab}

Golimumab is a fully human monoclonal antibody against TNF- $\alpha$ and is available for the treatment of psoriatic arthritis. ${ }^{98}$ One case report regarding the use of golimumab in EP has been published. The patient was given $50 \mathrm{mg}$ subcutaneously per month and by the third injection had an $82 \%$ reduction in PASI score. He was continued on therapy for $>11$ months and maintained his achieved results. No significant adverse events were reported throughout the duration of therapy. ${ }^{37}$

\section{IL-12/23 inhibitors \\ Ustekinumab}

Ustekinumab is a fully human monoclonal antibody that binds the p40 subunit of both IL-12 and IL-23. These two cytokines are involved in the pathogenesis of psoriasis by stimulating the Th1 and Th17 inflammatory pathways, respectively. Ustekinumab is approved for the treatment of moderate-to-severe plaque psoriasis and psoriatic arthritis and is administered subcutaneously. Appropriate dosing is $45 \mathrm{mg}$ for individuals weighing $<100 \mathrm{~kg}$ and $90 \mathrm{mg}$ for individuals weighing $\geq 100 \mathrm{~kg}$. The injections are administered at weeks 0 and 4 and then every 12 weeks thereafter. ${ }^{99}$ The 
published literature regarding the efficacy of ustekinumab in EP includes two multicenter retrospective studies, ${ }^{7,17}$ three case series, ${ }^{23,86,88}$ and three case reports..$^{55,87,100}$ Together, the studies comprise a total of 40 patients, with $32(80 \%)$ experiencing clinical improvement, as defined by a $75 \%$ reduction in PASI score from baseline. The earliest clinical improvements in these studies were seen after just 4 weeks of treatment ( $45 \%$ of cases). As mentioned in the section on adalimumab, several patients with relcacitrant EP that had failed treatment with other agents, including numerous forms of anti-TNF- $\alpha$ therapy, had eventual success with ustekinumab. ${ }^{17,55,86-88}$

\section{IL-I 7 inhibitors Ixekizumab}

Ixekizumab is a humanized IgG4 monoclonal antibody that inhibits IL-17A, an inflammatory cytokine of the Th17 pathway that has been implicated in the pathogenesis of psoriasis. ${ }^{101}$ Ixekizumab has been tested in Phase II and III clinical trials of moderate-to-severe plaque psoriasis, demonstrating efficacy comparable to that of other biologics. The drug has also more recently been tested in a Phase III, multicenter, single-arm, open-label study of eight EP patients. All subjects received a $160 \mathrm{mg}$ subcutaneous injection at week $0,80 \mathrm{mg}$ every 2 weeks through week 12 , and $80 \mathrm{mg}$ every 4 weeks through week 24 . The authors reported that at week 12, eight patients (100.0\%) achieved PASI75, five patients $(62.5 \%)$ achieved PASI90, and two patients $(25 \%)$ achieved PASI100. ${ }^{102}$

\section{Other biologics}

\section{Panitumumab}

Panitumumab is a human monoclonal antibody targeting the epidermal growth factor receptor (EGFR). A patient with recalcitrant EP who failed treatment with calcipotriol ointment, topical steroids, etretinate, and psoralen plus ultraviolet A showed dramatic improvement within 10 days of treatment with panitumumab. His achieved results lasted at least 6 months after the initiation of therapy. ${ }^{103}$ This case report suggests that EGFR signaling may contribute to the development of psoriatic skin lesions, and its role in the pathogenesis of EP could be further explored.

\section{Alefacept and efalizumab}

Alefacept and efalizumab are two biologics previously approved by the Food and Drug Administration for psoriasis that are no longer available. A case series following two patients has been published regarding the use of alefacept in
EP. Both patients had recalcitrant psoriasis that responded completely to a full course of alefacept. One of the patients achieved this response by 14 weeks, yet flared back to baseline 2 weeks after discontinuing treatment. The second patient was on a concomitant 13-week cyclosporine taper during which he maintained good results. ${ }^{104}$ Two patients treated with efalizumab as their first- and third-line biologic therapy, respectively, had no clinical benefit. ${ }^{7}$ On the other hand, one study in which efalizumab was administered at an initial subcutaneous weekly dose of $0.7 \mathrm{mg} / \mathrm{kg}$ followed by $1 \mathrm{mg} / \mathrm{kg}$ for 6 months reported PASI75 achievement in an EP patient after 18 weeks of treatment. ${ }^{105}$

\section{Discussion}

EP is a rare and severe disorder that is distinct from PV. Although the exact pathogenesis of EP is not fully understood, it is thought to involve a complex interplay of the Th1, Th2, and Th17 inflammatory pathways. Evidence suggests that in contrast to PV, the Th1/Th2 imbalance of EP tends to favor Th2 differentiation and its related cytokines. IL-4 and IL-13, in particular, have been shown to be elevated in EP relative to both PV patients and healthy controls. Functional studies involving these cytokines may help clarify their roles in the pathogenesis of EP. TNF- $\alpha$ is also an important player in the pathogenesis of EP especially given the documented efficacy of anti-TNF- $\alpha$ agents in disease treatment. Given the morbidity and potential mortality associated with the condition, there is a need for a better understanding of EP pathophysiology.

The management of EP begins with a comprehensive assessment of the patient's presentation. Often patients require supportive measures that address electrolyte abnormalities, nutritional status, impaired thermoregulation, and underlying infection, among other things. Furthermore, potential septic and thromboembolic complications justify close surveillance of patients and often also hospitalization. Severe and unstable cases of EP benefit from rapidly acting agents, such as cyclosporine and infliximab. Despite a comparably rapid onset of action, use of systemic steroids should be avoided given high risk of rebound after withdrawal. Although the most recent expert consensus only recommends acitretin and methotrexate as first-line therapies for stable cases, review of the literature suggests that ustekinumab may also be used in this role. Evidence supporting the efficacy of ustekinumab comes from 40 documented instances of EP in which the biologic was used as a monotherapy. Of these patients, $80 \%$ had a significant clinical response to treatment, while $45 \%$ began to exhibit improvement in as early as 4 weeks. Furthermore, $75 \%$ of responders had recalcitrant EP who previously failed therapy with other 
agents, including the TNF- $\alpha$ inhibitors that were also reviewed in this article. Given its response profile, ustekinumab may represent a viable option for the long-term control of EP. The antiTNF- $\alpha$ agents studied in EP include etanercept, adalimumab, infliximab, and golimumab. Infliximab is already accepted as a first-line systemic therapy for EP and has demonstrated its clinical efficacy in a large volume of patients; $65 \%$ of patients on infliximab had at least a $50 \%$ reduction in PASI score from baseline. Etanercept, adalimumab, and golimumab have all been employed in relatively fewer instances of EP but have also shown good clinical efficacy. In this regard, $67 \%$ of patients in the largest case series investigating etanercept in EP, 50\% of patients in the largest clinical study investigating adalimumab in EP, and one EP patient who received golimumab were noted to have at least a $75 \%$ reduction in PASI score from baseline.

The other biologics reviewed in this article have been tested in far fewer EP patients. Ixekizumab has been investigated in eight subjects. Although results suggest that ixekizumab shows great therapeutic promise, further largescale and long-term trials are needed to establish safety and efficacy. Other anti-IL-17 agents such as secukinumab and brodalumab may therefore also represent experimental therapeutic options for EP. Panitumumab, efalizumab, and alefacept were efficacious in $100 \%$ (one of one patient), $33.3 \%$ (one of three patients), and 100\% (two of two patients) of cases, respectively. The efficacy of panitumumab, an EGFR antagonist, alludes to a potential role that the EGFR may play in the pathogenesis of psoriasis. Further studies may be warranted to explore a possible pathophysiologic relationship. Regarding the remaining therapies reviewed in this article, topical steroids can be helpful adjuncts in both acute and later stages of EP, whereas phototherapy may be useful in later stages once the disease course stabilizes.

\section{Conclusion}

The treatment options for EP have greatly expanded in the last several years. However, additional controlled trials with extended follow-ups are needed to better understand the pathophysiology of EP, determine the exact role, safety, and efficacy of the new biologics in EP, and reinform treatment guidelines.

\section{Acknowledgments}

We would like to thank Kirsten Wong for her assistance in preparing this manuscript and Doctor Tina Bhutani for her critical review and edits. Doctor Wilson Liao is supported in part by grants from the National Institutes of Health (R01AR065174, U01AI119125).

\section{Disclosure}

Doctor Wilson Liao serves as a research investigator for Abbvie, Janssen, Pfizer, and Novartis. Doctor Liao has no stocks, employment, or board memberships with any pharmaceutical company. The other authors report no conflicts of interest in this work.

\section{References}

1. Christophers E. Psoriasis - epidemiology and clinical spectrum. Clin Exp Dermatol. 2001;26(4):314-320.

2. Boyd AS, Menter A. Erythrodermic psoriasis. Precipitating factors, course, and prognosis in 50 patients. J Am Acad Dermatol. 1989;21 (5 pt 1):985-991.

3. Burton J, Rook A, Wilkinson D. In: Rook A, Wilkinson D, Ebling F, editors. Eczema, Lichen Simplex, Erythroderma and Prurigo. In: Textbook of Dermatology. 4th ed. Boston: Blackwell; 1986:367-418.

4. Liu Y, Krueger JG, Bowcock AM. Psoriasis: genetic associations and immune system changes. Genes Immun. 2007;8(1):1-12.

5. Bhalerao J, Bowcock AM. The genetics of psoriasis: a complex disorder of the skin and immune system. Hum Mol Genet. 1998;7(10):1537-1545.

6. Hawilo A, Zaraa I, Benmously R, et al. Erythrodermie psoriasique: profil epidemio-clinique et therapeutique a propos de 60 cas. [Erythrodermic psoriasis: epidemiological clinical and therapeutic features about 60 cases]. Tunis Med. 2011;89(11):841-847. French.

7. Viguier $\mathrm{M}$, Pagès $\mathrm{C}$, Aubin $\mathrm{F}$, et al. Efficacy and safety of biologics in erythrodermic psoriasis: a multicentre, retrospective study. $\mathrm{Br} J$ Dermatol. 2012;167(2):417-423.

8. Rosenbach M, Hsu S, Korman NJ, et al. Treatment of erythrodermic psoriasis: from the medical board of the National Psoriasis Foundation. J Am Acad Dermatol. 2010;62(4):655-662.

9. Richetta AG, Maiani E, Carlomagno V, et al. Treatment of erythrodermic psoriasis in $\mathrm{HCV}+$ patient with adalimumab. Dermatol Ther. 2009;22(suppl 1):S16-S18.

10. Teran CG, Teran-Escalera CN, Balderrama C. A severe case of erythrodermic psoriasis associated with advanced nail and joint manifestations: a case report. J Med Case Rep. 2010;4:179.

11. Stinco G, Errichetti E. Erythrodermic psoriasis: current and future role of biologicals. BioDrugs. 2015;29(2):91-101.

12. Management of erythrodermic psoriasis with low-dose cyclosporin. Studio Italiano Multicentrico nella Psoriasi (SIMPSO). Dermatology. 1993;187(suppl 1):30-37.

13. Prystowsky JH, Cohen PR. Pustular and erythrodermic psoriasis. Dermatol Clin. 1995;13(4):757-770.

14. Evans AV, Parker JC, Russell-Jones R. Erythrodermic psoriasis precipitated by radiologic contrast media. J Am Acad Dermatol. 2002;46(6):960-961.

15. Zhang F, Li H, Zhou Y, GuY, Wang L. Caveolin-1 expression in different types of psoriatic lesions: analysis of 66 cases. Indian J Dermatol. 2014;59(3):225-229.

16. Cox NH, Gordon PM, Dodd H. Generalized pustular and erythrodermic psoriasis associated with bupropion treatment. Br J Dermatol. 2002;146(6):1061-1063.

17. Pescitelli L, Dini V, Gisondi P, et al. Erythrodermic psoriasis treated with ustekinumab: an Italian multicenter retrospective analysis. J Dermatol Sci. 2015;78(2):149-151.

18. Griffiths C, Barker J. In: Burns T, Breathnach S, Cox N, Griffiths C, editors. Psoriasis. In: Rooks Textbook of Dermatology. 8th ed. Oxford: Wiley Blackwell; 2010: 1731-1800.

19. Patil JD, Chaudhary SS, Rani N, Mishra AK. Follicular psoriasis causing erythroderma in a child: a rare presentation. Indian Dermatol Online J. 2014;5(1):63-65.

20. Kumar P, Thomas J, Dineshkumar D. Histology of psoriatic erythroderma in infants: analytical study of eight cases. Indian J Dermatol. 2015;60(2):213. 
21. Chang SE, Choi JH, Koh JK. Congenital erythrodermic psoriasis. $\mathrm{Br}$ J Dermatol. 1999;140(3):538-539.

22. Chiricozzi A, Saraceno R, Cannizzaro MV, Nisticò SP, Chimenti S, Giunta A. Complete resolution of erythrodermic psoriasis in an HIV and $\mathrm{HCV}$ patient unresponsive to antipsoriatic treatments after highly active antiretroviral therapy (Ritonavir, Atazanavir, Emtricitabine, Tenofovir). Dermatology. 2012;225(4):333-337.

23. Wang T-S, Tsai T-F. Clinical experience of ustekinumab in the treatment of erythrodermic psoriasis: a case series. J Dermatol. 2011;38(11):1096-1099.

24. Strober BE, Clay Cather J, Cohen D, et al. A Delphi consensus approach to challenging case scenarios in moderate-to-severe psoriasis: part 2. Dermatol Ther (Heidelb). 2012;2(1):2.

25. Liu M, Li J-H, Li B, He C-D, Xiao T, Chen H-D. Coexisting gout, erythrodermic psoriasis and psoriatic arthritis. Eur J Dermatol. 2009; 19(2):184-185.

26. Bruzzese V, Pepe J. Efficacy of cyclosporine in the treatment of a case of infliximab-induced erythrodermic psoriasis. Int J Immunopathol Pharmacol. 2009;22(1):235-238.

27. Ahdout J, Mandel H, Chiu M. Erythroderma in a patient taking acitretin for plaque psoriasis. J Drugs Dermatol. 2008;7(4):391-394.

28. Nestle FO, Kaplan DH, Barker J. Psoriasis. NEngl J Med. 2009;361(5): 496-509.

29. Li L-F, Sujan SA, Yang H, Wang W-H. Serum immunoglobulins in psoriatic erythroderma. Clin Exp Dermatol. 2005;30(2):125-127.

30. Zhang P, Chen H, Duan Y, et al. Analysis of Th1/Th2 response pattern for erythrodermic psoriasis. J Huazhong Univ Sci Technolog Med Sci. 2014;34(4):596-601.

31. Deeva I, Mariani S, De Luca C, et al. Wide-spectrum profile of inflammatory mediators in the plasma and scales of patients with psoriatic disease. Cytokine. 2010;49(2):163-170.

32. Ghoreschi K, Mrowietz U, Röcken M. A molecule solves psoriasis? Systemic therapies for psoriasis inducing interleukin 4 and Th2 responses. J Mol Med (Berl). 2003;81(8):471-480.

33. Kano Y, TerakiY, Shiohara T. Dramatic improvement of psoriatic erythroderma after acute hepatitis: analysis of cytokine synthesis capability in peripheral blood T cells. Br J Dermatol. 2006;155(2):455-459.

34. Edlich RF, Fisher AL, Chase ME, Brock CM, Gubler KD, Long WB. Modern concepts of the diagnosis and treatment of psoriasis. JEnviron Pathol Toxicol Oncol. 2009;28(3):235-240.

35. Nograles KE, Zaba LC, Guttman-Yassky E, et al. Th17 cytokines interleukin (IL)-17 and IL-22 modulate distinct inflammatory and keratinocyte-response pathways. Br J Dermatol. 2008;159(5):1092-1102.

36. Moy AP, Murali M, Kroshinsky D, Duncan LM, Nazarian RM. Immunologic overlap of helper T-cell subtypes 17 and 22 in erythrodermic psoriasis and atopic dermatitis. JAMA Dermatol. 2015;151(7): 753-760.

37. Lee W-K, Kim G-W, Cho H-H, et al. Erythrodermic psoriasis treated with golimumab: a case report. Ann Dermatol. 2015;27(4):446-449.

38. Groves RW, Kapahi P, Barker JN, Haskard DO, MacDonald DM. Detection of circulating adhesion molecules in erythrodermic skin disease. J Am Acad Dermatol. 1995;32(1):32-36.

39. McElhenny BE, Todd DJ, McCance D, Young I, Burrows D. Erythrodermic psoriasis. Report of a case associated with symptomatic hypophosphataemia. Clin Exp Dermatol. 1993;18(2):167-168.

40. Levin E, Sako E, Famenini S, Wu J. In: Koo J, Levin E, Leon A, Wu J, Gottlieb A, editors. Erythrodermic and Pustular Psoriasis. In: Moderate to Severe Psoriasis. 4th ed. Boca Raton: CRC Press; 2014:277-288

41. Peters BP, Weissman FG, Gill MA. Pathophysiology and treatment of psoriasis. Am J Health Syst Pharm. 2000;57(7):645-659. quiz 660-661.

42. Arbiser JL, Grossman K, Kaye E, Arndt KA. Use of short-course class 1 topical glucocorticoid under occlusion for the rapid control of erythrodermic psoriasis. Arch Dermatol. 1994;130(6):704-706.

43. Vaidya TS, Lewallen RS, Feldman SR. Erythrodermic psoriasis and severe hypotension requiring intensive care unit hospitalization: poor treatment outcome as a result of poor adherence. J Dermatolog Treat. 2015;27(2):134-135.
44. Scott LJ, Dunn CJ, Goa KL. Calcipotriol ointment. A review of its use in the management of psoriasis. Am J Clin Dermatol. 2001;2(2):95-120.

45. Bolognia J, Jorizzo J, Rapini R. Psoriasis. In: Hodgson S, editor. Dermatology. 1st ed. London: Mosby; 2003:135-156.

46. van der Vleuten CJ, Gerritsen MJ, Steijlen PM, de Jong EM, van de Kerkhof PC. A therapeutic approach to erythrodermic psoriasis: report of a case and a discussion of therapeutic options. Acta Derm Venereol. 1996;76(1):65-67.

47. Mumoli N, Vitale J, Gambaccini L, Sabatini S, Brondi B, Cei M. Erythrodermic psoriasis. QJM. 2014;107(4):315.

48. Racz E, Prens EP. Phototherapy and photochemotherapy for psoriasis. Dermatol Clin. 2015;33(1):79-89.

49. Pang M-L, Murase JE, Koo J. An updated review of acitretin - a systemic retinoid for the treatment of psoriasis. Expert Opin Drug Metab Toxicol. 2008;4(7):953-964.

50. Orfanos CE, Zouboulis CC, Almond-Roesler B, Geilen CC. Current use and future potential role of retinoids in dermatology. Drugs. 1997;53(3):358-388.

51. Kaplan YC, Ozsarfati J, Etwel F, Nickel C, Nulman I, Koren G. Pregnancy outcomes following first-trimester exposure to topical retinoids: a systematic review and meta-analysis. Br J Dermatol. 2015;173(5): 1132-1141.

52. Koo J. Systemic sequential therapy for psoriasis: a new paradigm for improved therapeutic results. JAm Acad Dermatol. 1999;3(2):25-28.

53. Geiger JM, Czarnetzki BM. Acitretin (Ro 10-1670, etretin): overall evaluation of clinical studies. Dermatologica. 1988;176(4): 182-190.

54. Polat M, Sereflican B. A case of elephantiasis nostras verrucosa treated by acitretin. J Drugs Dermatol. 2012;11(3):402-405.

55. Castiñeiras I, Fernández-Diaz L, Juárez Y, Lueiro M. Sustained efficacy of ustekinumab in refractory erythrodermic psoriasis after failure of antitumor necrosis factor therapies. J Dermatol. 2012;39(8): 730-731.

56. Kokelj F, Plozzer C, Torsello P, Trevisan G. Efficacy of cyclosporine plus etretinate in the treatment of erythrodermic psoriasis (three case reports). J Eur Acad Dermatol Venereol. 1998;11(2):177-179.

57. Kuijpers AL, van Dooren-Greebe JV, van de Kerkhof PC. Failure of combination therapy with acitretin and cyclosporin A in 3 patients with erythrodermic psoriasis. Dermatology. 1997;194(1):88-90.

58. Takahashi MDF, Castro LGM, Romiti R. Infliximab, as sole or combined therapy, induces rapid clearing of erythrodermic psoriasis. $\mathrm{Br}$ J Dermatol. 2007;157(4):828-831.

59. Mahé E, Descamps V, Baïkian B, Toulon A, Crickx B. Acitretin-induced erythroderma in a psoriatic patient. $J$ Eur Acad Dermatol Venereol. 2006;20(9):1133-1134.

60. Levin J, Almeyda J. Erythroderma due to etretinate. Br J Dermatol. 1985;112(3):373.

61. Preiss JC, Zouboulis CC, Zeitz M, Duchmann R. Schwere psoriatische Erythrodermie bei 22q11-Deletionssyndrom. [Severe erythrodermic psoriasis in a patient with 22q11 deletion syndrome]. Med Klin (Munich). 2005;100(5):275-278. German.

62. Mahmood T, Zaghi D, Menter A. Emerging oral drugs for psoriasis. Expert Opin Emerg Drugs. 2015;20(2):209-220.

63. Khaled A, Ben Hamida M, Zeglaoui F, Kharfi M, Ezzine N, Fazaa B. Traitement du psoriasis par méthotrexate à l'ère des biothérapies : étude chez 21 patients tunisiens. [Treatment of psoriasis by methotrexate in the era of biotherapies: a study in 21 Tunisian patients]. Thérapie. 2012;67(1):49-52. French.

64. Fraga NA, Paim Mde F, Follador I, Ramos AN, Rêgo VR. Refractory erythrodermic psoriasis in a child with an excellent outcome by using etanercept. An Bras Dermatol. 2011;86(4 suppl 1):S144-S147.

65. Van Dooren-Greebe RJ, Kuijpers AL, Mulder J, De Boo T, Van de Kerkhof PC. Methotrexate revisited: effects of long-term treatment in psoriasis. Br J Dermatol. 1994;130(2):204-210.

66. Haustein UF, Rytter M. Methotrexate in psoriasis: 26 years' experience with low-dose long-term treatment. $J$ Eur Acad Dermatol Venereol. 2000;14(5):382-388. 
67. Collins $\mathrm{P}$, Rogers $\mathrm{S}$. The efficacy of methotrexate in psoriasis - a review of 40 cases. Clin Exp Dermatol. 1992;17(4):257-260.

68. Si X, Ge L, Xin H, Cao W, Sun X, Li W. Erythrodermic psoriasis with bullous pemphigoid: combination treatment with methotrexate and compound glycyrrhizin. Diagn Pathol. 2014;9:102.

69. Arsiwala S. Infliximab: efficacy in psoriasis. Indian J Dermatol Venereol Leprol. 2013;79(suppl 7):S25-S34.

70. Heikkilä H, Ranki A, Cajanus S, Karvonen S-L. Infliximab combined with methotrexate as long-term treatment for erythrodermic psoriasis. Arch Dermatol. 2005;141(12):1607-1610.

71. Huskić J, Alendar F. Tissue angiotensin-converting enzyme in patients with various clinical forms of psoriasis. Bosn J Basic Med Sci. 2007;7(2):103-106.

72. Tuyp E, MacKie RM. Combination therapy for psoriasis with methotrexate and etretinate. J Am Acad Dermatol. 1986;14(1):70-73.

73. Aydin F, Canturk T, Senturk N, Turanli AY. Methotrexate and ciclosporin combination for the treatment of severe psoriasis. Clin Exp Dermatol. 2006;31(4):520-524.

74. Marqueling AL, Cordoro KM. Systemic treatments for severe pediatric psoriasis: a practical approach. Dermatol Clin. 2013;31(2): 267-288.

75. Sprecher E, Bergman R, Friedman-Birnbaum R. Cyclosporine treatment of psoriatic erythroderma complicated by bacterial sepsis. $J$ Eur Acad Dermatol Venereol. 1999;12(2):197-198.

76. Borghi A, Corazza M, Mantovani L, Bertoldi AM, Giari S, Virgili A. Prolonged cyclosporine treatment of severe or recalcitrant psoriasis: descriptive study in a series of 20 patients. Int $J$ Dermatol. 2012;51(12):1512-1516.

77. Zhou Y, Rosenthal D, Dutz J, Ho V. Mycophenolate mofetil (CellCept) for psoriasis: a two-center, prospective, open-label clinical trial. $J$ Cutan Med Surg. 2003;7(3):193-197.

78. Geilen CC, Tebbe B, Garcia Bartels C, Krengel S, Orfanos CE. Successful treatment of erythrodermic psoriasis with mycophenolate mofetil. Br J Dermatol. 1998;138(6):1101-1102.

79. Akhyani M, Chams-Davatchi C, Hemami MR, Fateh S. Efficacy and safety of mycophenolate mofetil vs. methotrexate for the treatment of chronic plaque psoriasis. J Eur Acad Dermatol Venereol. 2010;24(12):1447-1451.

80. Geilen CC, Arnold M, Orfanos CE. Mycophenolate mofetil as a systemic antipsoriatic agent: positive experience in 11 patients. $\mathrm{Br} J$ Dermatol. 2001;144(3):583-586.

81. Fotiadou C, Lazaridou E, Ioannides D. Management of psoriasis in adolescence. Adolesc Health Med Ther. 2014;5:25-34.

82. Esposito M, Mazzotta A, de Felice C, Papoutsaki M, Chimenti S. Treatment of erythrodermic psoriasis with etanercept. Br J Dermatol. 2006;155(1):156-159.

83. Piqué-Duran E, Pérez-Cejudo JA. Eritrodermia psoriásica tratada con etanercept. [Psoriatic erythroderma treated with etanercept]. Actas Dermosifiliogr. 2007;98(7):508-510. Spanish.

84. Romero-Maté A, García-Donoso C, Martinez-Morán C, HernándezNúñez A, Borbujo J. Long-term management of erythrodermic psoriasis with anti-TNF agents. Dermatol Online J. 2010;16(6):15.

85. Leonardi C, Papp K, Strober B, et al. The long-term safety of adalimumab treatment in moderate to severe psoriasis: a comprehensive analysis of all adalimumab exposure in all clinical trials. Am J Clin Dermatol. 2011;12(5):321-337.

86. Saraceno R, Talamonti M, Galluzzo M, Chiricozzi A, Costanzo A, Chimenti S. Ustekinumab treatment of erythrodermic psoriasis occurring after physical stress: a report of two cases. Case Rep Dermatol. 2013;5(3):254-259.
87. Buggiani G, D'Erme AM, Krysenka A, Pescitelli L, Lotti T, Prignano F. Efficacy of ustekinumab in sub-erythrodermic psoriasis: when TNFblockers fail. Dermatol Ther. 2012;25(3):283-285.

88. Santos-Juanes J, Coto-Segura P, Mas-Vidal A, Galache Osuna C. Ustekinumab induces rapid clearing of erythrodermic psoriasis after failure of antitumour necrosis factor therapies. Br J Dermatol. 2010;162(5):1144-1146.

89. Gall JS, Kalb RE. Infliximab for the treatment of plaque psoriasis. Biologics. 2008;2(1):115-124.

90. Lewis TG, Tuchinda C, Lim HW, Wong HK. Life-threatening pustular and erythrodermic psoriasis responding to infliximab. J Drugs Dermatol. 2006;5(6):546-548.

91. Valdés AMDP, Schroeder HF, Roizen GV, Honeyman MJ, Sánchez ML. Eficacia y seguimiento en el largo plazo de pacientes con psoriasis vulgar moderada a severa en tratamiento con infliximab. [Efficacy of infliximab in patients with moderate and severe psoriasis treated with infliximab (Remicade)]. Rev Med Chil. 2006;134(3):326-331. Spanish.

92. Fiehn C. Case number 29: hitting three with one strike: rapid improvement of psoriatic arthritis, psoriatic erythroderma, and secondary renal amyloidosis by treatment with infliximab (Remicade). Ann Rheum Dis. 2004;63(3):232-232.

93. O'Quinn RP, Miller JL. The effectiveness of tumor necrosis factor alpha antibody (infliximab) in treating recalcitrant psoriasis: a report of 2 cases. Arch Dermatol. 2002;138(5):644-648.

94. Rongioletti F, Borenstein M, Kirsner R, Kerdel F. Erythrodermic, recalcitrant psoriasis: clinical resolution with infliximab. J Dermatolog Treat. 2003;14(4):222-225.

95. Torii H, Nakagawa H. Japanese Infliximab Study Investigators. Longterm study of infliximab in Japanese patients with plaque psoriasis, psoriatic arthritis, pustular psoriasis and psoriatic erythroderma. $J$ Dermatol. 2011;38(4):321-334.

96. Poulalhon N, Begon E, Lebbé C, et al. A follow-up study in 28 patients treated with infliximab for severe recalcitrant psoriasis: evidence for efficacy and high incidence of biological autoimmunity. Br J Dermatol. 2007;156(2):329-336.

97. Lisby S, Gniadecki R. Infliximab (Remicade) for acute, severe pustular and erythrodermic psoriasis. Acta Derm Venereol. 2004;84(3):247-248.

98. Papagoras C, Voulgari PV, Drosos AA. Golimumab, the newest TNF- $\alpha$ blocker, comes of age. Clin Exp Rheumatol. 2015;33(4):570-577.

99. Alunno A, Carubbi F, Cafaro G, et al. Targeting the IL-23/IL-17 axis for the treatment of psoriasis and psoriatic arthritis. Expert Opin Biol Ther. 2015;15(12):1727-1737.

100. Koutsoukou X-A, Papadavid E, Theodoropoulos K, Rigopoulos D. Ustekinumab in severe complicated erythrodermic psoriasis: rapid clearing, safety, and sustained remission. Dermatol Ther. 2014;27(5): 257-259.

101. Ren V, Dao H. Potential role of ixekizumab in the treatment of moderate-to-severe plaque psoriasis. Clin Cosmet Investig Dermatol. 2013;6:75-80.

102. Saeki H, Nakagawa $H$, Ishii $T$, et al. Efficacy and safety of open-label ixekizumab treatment in Japanese patients with moderate-to-severe plaque psoriasis, erythrodermic psoriasis and generalized pustular psoriasis. J Eur Acad Dermatol Venereol. 2015;29(6):1148-1155.

103. Nishizawa A, Satoh T, Yokozeki H. Erythrodermic psoriasis improved by panitumumab, but not bevacizumab. Acta Derm Venereol. 2012; 92(4):360-361.

104. Prossick TA, Belsito DV. Alefacept in the treatment of recalcitrant palmoplantar and erythrodermic psoriasis. Cutis. 2006;78(3):178-180.

105. Piccirillo F, Stinco G, Patrone P. Erythrodermic psoriasis successfully treated with efalizumab. Eur J Dermatol. 2008;18(3):357-358. 


\section{Publish your work in this journal}

Psoriasis: Targets and Therapy is international, peer-reviewed, open access journal focusing on psoriasis, nail psoriasis, psoriatic arthritis and related conditions, identification of therapeutic targets and the optimal use of integrated treatment interventions to achieve improved outcomes

and quality of life. Visit http://www.dovepress.com/testimonials.php to read real quotes from published authors.

Submit your manuscript here: https://www.dovepress.com/psoriasis-targets-and-therapy-journal 